\title{
Koneksi Politik dan Aggresivitas Pajak: Fenomena di Indonesia
}

\author{
Agung Prasetyo Nugroho Wicaksono \\ Universitas Airlangga \\ agung_success@yahoo.com
}

\begin{abstract}
This paper examines the effect of political connections and tax agressiveness in Indonesia. We used precentage of goverment ownership and firm's directors who have informal ties with leading politicans or goverment for measuring political connections. The effective tax rates used for measurements of tax agressiveness. Data of this research is secondary data from annual report listed on Indonesia Stock Exchange with 148 listed companies in period 2013 - 2015. Method of analysis used panel data estimation prosedures. We find firms with political connections pay tax at significantly higher effective tax rates than the other firms.
\end{abstract}

Keywords : political connection, tax agressiveness, effective tax rate

\begin{abstract}
Abstrak
Penelitian ini menguji dampak koneksi politik terhadap agresivitas pajak di Indonesia. Peneliti menggunakan kepemilikan pemerintah dan direksi yang memiliki hubungan informal dengan politisi atau pemerintah untuk mengukur koneksi politik. Tarif pajak efektif digunakan untuk mengukur agresivitas pajak. Data penelitian berdasarkan data sekunder berupa laporan tahunan pada Bursa Efek Indonesia dengan menggunakan 148 perusahaan periode 2013 - 20I5. Metode analisis yang digunakan adalah dengan prosedur estimasi data panel. Peneliti menemukan bahwa perusahaan yang berkoneksi politik membayar pajak lebih efektif dibanding perusahan yang tidak berkoneksi politik.
\end{abstract}

Kata kunci : koneksi politik, agresivitas pajak, tarif pajak efektif.

Diterima: 20 Januari 2017; Revisi: 3 Maret 2017; Disetujui: 30 Maret 2017 


\section{PENDAHULUAN}

Semenjak reformasi perpajakan dijalankan dengan dikeluarkanya undang-undang perpajakan yang baru tahun 1983, sistem perpajakan berubah dari office assessment menjadi self assessment (misalnya untuk Pajak Penghasilan dan Pajak Pertambahan Nilai). Dengan sistem yang baru ini, wajib pajak memiliki hak dan kewajiban baik dalam menghitung, membayar, dan melaporkan sendiri jumlah kewajiban perpajakannya. Hal ini akan terlaksana dengan baik apabila wajib pajak mematuhi peraturan perpajakan sesuai undang-undang yang berlaku. Jika dilihat dari sudut pandang pemerintah, pajak merupakan salah satu sumber penerimaan penting yang digunakan sebagai pembiayaan dan pembangunan negara. Jika pajak yang diharapkan tidak sesuai dengan ekspektasi, maka proses pembiayaan pengeluaran negara serta proses pengeluaran untuk pembangunan akan terhambat. Sebaliknya, dari sisi perusahaan, pajak merupakan suatu beban yang akan mengurangi laba sebelum pajak.

Salah satu upaya yang dilakukan perusahaan adalah dengan meminimalkan beban pajak dalam batas yang tidak melanggar peraturan, karena pajak merupakan salah satu faktor pengurang laba. Besarnya pajak seperti kita ketahui, tergantung kepada besarnya penghasilan. Semakin besar penghasilan, semakin besar pula pajak terutang. Oleh karena itu, perusahaan membutuhkan perencanaan pajak (tax Planning) yang tepat agar perusahaan membayar pajak dengan baik, benar dan efisien. Untuk mencapai kepentingan tersebut, salah satu cara yang dilakukan adalah dengan melakukan agresivitas pajak (tax aggresiveness).

Agresivitas pajak adalah perencanaan pajak yang ditujukan untuk menurunkan laba kena pajak (Frank, Lynch, \& Rego, 2009) dan dilakukan sebagai pemenuhan kewajiban perpajakan yang masih sesuai dengan peraturan perpajakan (lawful). Hal tersebut berbeda dengan tax evasion (penggelapan atau penyelundupan pajak). Tax evasion adalah upaya wajib pajak menghindari pajak terutang secara ilegal dengan cara menyembunyikan keadaan yang sebenarnya. Agresivitas pajak mengarah kepada bagaimana upaya penghindaran pajak secara legal dan aman karena tidak bertentangan dengan peraturan perpajakan serta mengungkapkan informasi secara penuh kepada 
otoritas pajak. Metode dan teknik yang digunakan adalah cenderung memanfaatkan kelemahan-kelemahan (grey area) yang terdapat dalam undang-undang dan peraturan perpajakan itu sendiri dan tidak melanggar hukum perpajakan.

Secara teori, suatu individu akan dipengaruhi oleh berbagai faktor didalam mematuhi pajak, yaitu : tingkat tarif pajak, probabilitas terdeteksi melakukan penghindaran pajak, denda atau hukuman, dan ketidak inginan menanggung suatu resiko (Hanlon \& Heitzman, 2010). Agresivitas pajak juga dipengaruhi oleh berbagai faktor lain, yakni karakter eksekutif dan ukuran perusahaan (Swingly \& Sukartha, 2015) dalam (Widagdo \& Pranoto, 2016). (Dyreng, Hanlon, \& Maydew, 2010) juga berpendapat bahwa karakter eksekutif juga mampu mempengaruhi perusahaan melakukan agresivitas pajak. Menurut (Zhang, Li, \& Jian, 20I2), "bahwa perusahaan yang dimiliki pemerintah dan berkoneksi politik mempunyai tingkat penghindaran pajak yang lebih rendah jika dibandingkan dengan perusahaan yang tidak dimiliki pemerintah.

Dampak koneksi politik terhadap tindakan penghindaran pajak melalui aggresivitas pajak sebagaian besar jarang diketahui dalam literatur akademis. Perusahaan yang melakukan koneksi politik, pada umumnya seringkali melakukan tindakan agresivitas pajak. Hal tersebut dilakukan perusahaan tersebut agar memiliki resiko deteksi yang lebih rendah karena politisi juga memberikan perlindungan terhadap perusahan yang terhubung denganya agar resiko penghindaran pajaknya bisa lebih rendah. Kemudian perusahaan dapat memiliki informasi yang lebih baik mengenai perubahan peraturan perpajakan dimasa yang akan datang. Dampak yang dirasakan pula adalah rendahnya tekanan dari pasar modal untuk melakukan transparansi serta berpotensi menurunkan biaya politik terkait kegiatan perencanaan pajak melalui agresivitas pajak. Koneksi politik juga bermanfaat bagi perusahaan untuk mendapatkan akses ke pemerintah pusat(Kim \& Zhang, 20I5).

Koneksi politik sering terjadi di negara-negara berkembang yang dimana koneksi politik tersebut dilakukan dengan menempatkan pihak yang memiliki kedekatan dengan pihak pemerintah, sehingga pihak pemerintah tersebut memiliki koneksi terhadap struktur organisasi perusahaan, apakah itu komisaris maupun ataupun direksi (Fisman, 200I). Di Indonesia, hal tersebut sering kali terjadi pada perusahaan Badan Usaha Milik 
Negara (BUMN). Sejak zaman presiden Soeharto sampai dengan presiden Joko Widodo saat ini pun sudah melakukan sejumlah pengisian maupun pergantian komisaris BUMN yang memiliki koneksi dengan pemerintah dengan mengangkat komisaris BUMN yang berasal dari para relawan maupun dari anggota partai politik untuk menduduki jabatan sebagai komisaris BUMN. Hal tersebut menunjukkan bahwa fenomena koneksi politik adalah hal yang sangat umum dilakukan pada struktur organisasi perusahaan BUMN di Indonesia.

\section{LANDASAN TEORI DAN PENGEMBANGAN HIPOTESIS}

\section{Teori Agensi}

Perusahaan yang semakin besar dan terbuka maka akan nampak pemisahaan kekayaan antara pemilik dengan perusahaan. Pemilik perusahaan memberikan delegasi kepada manajemen dalam mengelola kekayaan perusahaan. Pendelegasian tersebut harus membuat manajer harus mengelola serta mengambil keputusan atas nama perusahaan. Agency theory menerangkan suatu hubungan antara pemberi kerja dengan penerima kerja untuk melaksanakan pekerjaan. Suatu pemberi kerja disebut principal yang dimana akan memberikan hak kepada orang lain yang disebut sebagai agent untuk menjalankan haknya (Jensen, 1986). Kedua belah pihak tersebut diikat oleh suatu kontrak kerja yang menyatakan hak dan kewajibanya masing-masing.

Istilah yang sering digunakan di dalam menggambarkan agency theory yakni principal sebagai pemegang saham dan agent sebagai manajemen yang mengelola perusahaan. Kemudian, dalam mewujudkan kontrak kerja yang dimaksud, maka pemegang saham menyediakan fasilitas dan dana untuk kebutuhan operasi perusahaan. Pihak agent sebagai pengelola perusahaan yang dipimpin oleh seorang manajer memiliki kewajiban untuk melakukan pengelolaan operasional perusahaan sebagaimana diamanahkan oleh para pemegang saham (principal). Upaya di dalam peningkatan kemakmuran pemegang saham dapat melalui peningkatan nilai perusahaan. Berikut sebagai imbalan adalah manajer akan memperoleh gaji, bonus, dan berbagai kompensasi lainya (Jensen, 1986).

Pada penelitian ini, teori agensi menjelaskan bahwa adanya perbedaan kepentingan yang muncul antara pemilik utama perusahaan yaitu pemerintah yang berperan juga sebagai pembuat regulasi dalam hal perpajakan dengan pihak manajemen 
perusahaan yang berperan sebagai pembayar pajak. Pemerintah segabai pemilik utama perusahaan berharap akan adanya pemasukan yang sebesar-besarnya dari sektor pajak yang disisi lain pada pihak manajemen memiliki pandangan bahwa perusahaan harus menghasilkan laba yang signifikan dengan beban pajak yang serendah-rendahnya. Perbedaan sudut pandang tersebut tentunya akan menghasilkan konflik diantara pemerintah sebagai pemilik perusahaan dengan manajemen perusahaan.

\section{Political Favoritism Effect dan Bureaucratic Incentive Effect}

Terdapat 2 sisi yang menghubungkan antara koneksi politik dengan tax agreessiveness (Zhang et al., 20I2). Yang pertama adalah koneksi politik yang dilakukan oleh BUMN adalah untuk melakukan lobby dengan pemerintah untuk menghindari pemeriksaan pajak, pengajuan pengurangan denda pajak maupun tindakan lain yang tergolong tax evasion atau tax agreesiveness. Koneksi politik yang dilakukan akan memberikan pengaruh baik terhadap tax agreesiveness yang disebut Political Favoritism Effect. Kedua, pemerintah memiliki wewenang untuk menetapkan dan mengevaluasi pihak-pihak eksekutif di BUMN, baik dewan komisaris maupun dewan direksi. Penghargaan juga diberikan kepada BUMN yang memberikan kontribusi pembayaran pajak yang tinggi. Fenomena tersebut juga sudah terjadi di Indonesia. Hal tersebut membuktikan bahwa pemerintah berperan dominan di dalam berkoneksi politik sehingga memberikan pengaruh kurang baik terhadap tindakan tax agressiveness sehingga hal tersebut disebut dengan Bureaucratic Incentive Effect.

\section{Koneksi Politik}

Perusahaan yang melakukan koneksi politik adalah persuahaan yang mempunyai hubungan istimewa dengan pemerintah (Gomez, 2009) dalam (Widagdo \& Pranoto, 2016). Hubungan istimewa dengan pemerintah dapat diartikan sebagai perusahaan milik pemerintah, bisa dalam berbentuk Badan Usaha Milik Negara (BUMN) maupun Badan Usaha Milik Daerah (BUMD). Hubungan istimewa antara pemilik perusahaan dengan pemerintah tentunya pemilik perusahaan adalah tokoh politik yang terkemuka yang dimana merupakan anggota dewan baik itu di pemerintahaan pusat maupun daerah ataupun sebagai anggota partai politik (Gomez, 2009).

Perusahaan yang melakukan koneksi politik, pada umumnya seringkali melakukan tindakan agresivitas pajak. Hal tersebut dilakukan perusahaan tersebut agar 
memiliki resiko deteksi yang lebih rendah karena politisi juga memberikan perlindungan terhadap perusahan yang terhubung denganya agar resiko penghindaran pajaknya bisa lebih rendah. Kemudian perusahaan dapat memiliki informasi yang lebih baik mengenai perubahan peraturan perpajakan dimasa yang akan datang. Dampak yang dirasakan pula adalah rendahnya tekanan dari pasar modal untuk melakukan transparansi serta berpotensi menurunkan biaya politik terkait kegiatan perencanaan pajak melalui agresivitas pajak. Tidak hanya itu, bahwa koneksi politik juga bermanfaat bagi perusahaan untuk mendapatkan akses ke pemerintah pusat (Kim \& Zhang, 20I5).

\section{Agresivitas Pajak}

Agresivitas pajak adalah perencanaan pajak yang ditujukan untuk menurunkan laba kena pajak (Frank et al., 2009) dan dilakukan sebagai pemenuhan kewajiban perpajakan yang masih sesuai dengan peraturan perpajakan (lawful). Hal tersebut berbeda dengan tax evasion (penggelapan atau penyelundupan pajak). Tax evasion adalah upaya wajib pajak menghindari pajak terutang secara ilegal dengan cara menyembunyikan keadaan yang sebenarnya. Agresivitas pajak mengarah kepada bagaimana upaya penghindaran pajak secara legal dan aman karena tidak bertentangan dengan peraturan perpajakan serta mengungkapkan informasi secara penuh kepada otoritas pajak. Metode dan teknik yang digunakan adalah cenderung memanfaatkan kelemahan-kelemahan (grey area) yang terdapat dalam undang-undang dan peraturan perpajakan itu sendiri dan tidak melanggar hukum perpajakan.

Dalam penelitian ini, agresivitas pajak diukur dengan tarif pajak efektif (Effective Tax Rate) dimana ETR merupakan tarif yang sesungguhnya berlaku atas penghasilan wajib pajak perusahaan dan berlaku pada industri yang bervariasi (Mclntyre \& Nguyen, 2000). Tarif pajak efektif perusahaan sering digunakan oleh para pembuat kebijakan dan pihak yang berkepentingan sebagai alat untuk membuat kesimpulan tentang sistem pajak perusahaan karena tarif pajak efektif memberikan ringkasan statistik yang mudah atas efek kumulatif dari pemberian berbagai insentif pajak dan perubahan tingkat pajak penghasilan pajak. 


\section{Pengembangan Hipotesis}

Koneksi politik mampu memberikan dampak positif maupun negatif terhadap tax agressiveness. Dampak positif dari koneksi politik adalah mendapatkan perlakuan istimewa dari pemerintah dalam hal perpajakan seperti menghindari audit pajak (Kim \& Zhang, 20I5). Pada sisi lain, koneksi politik juga berpengaruh negatif terhadap tax agressiveness. Para anggota eksekutif BUMN, baik itu dewan komisaris maupun dewan direksi ditetapkan dan dievaluasi oleh pemerintah. Meskipun terdapat beberapa hal yang menjadi pertimbangan dalam mengevaluasi, salah satu pertimbangan pemerintah adalah kontribusi BUMN terhadap penerimaan negara melalui pembayaran pajak (Kim \& Zhang, 20I5). Pemerintah juga memberikan apresiasi berupa penghargaan yang diberikan kepada BUMN yang berkontribusi besar terhadap negara melalui pembayaran pajak yang tinggi (Kim \& Zhang, 20I5).

Melihat fenomena tersebut, perusahaan BUMN akan saling berkompetisi satu sama lain dengan perusahaan BUMN lainya agar mampu memberikan kontribusi besar kepada negara melalui pembayaran pajak yang tinggi. Hal itu akan membuat para dewan komisaris maupun direktur akan tetapi dipertahankan atau diberikan hak promosi ke perusahaan BUMN yang lebih besar serta mempertegas legitimasi politiknya. Berdasarkan penjelasan diatas, maka hipotesis penelitian adalah sebagai berikut.

$\mathbf{H}_{\mathbf{1}}=$ koneksi politik berpengaruh negatif terhadap agresivitas pajak

\section{METODE}

Metode penenilitian yang digunakan dalam penelitian ini adalah metode penelitian kuantitatif. Metode kuantitatif adalah pendekatan ilmiah yang memandang suatu realitas yang dapat diklarifikasikan, konkrit, teramati, terukur, dan hubungan variabelnya bersifat sebab akibat dimana data penelitiannya berupa angka-angka dan analisisnya menggunakan statistik (Sugiyono, 2007).

Jenis data yang digunakan dalam penelitian ini adalah jenis data kuantitatif, yang diukur dengan suatu skala numerik berupa data interval dan data rasio. Menurut dimensi waktu (Kuncoro, 2003), jenis data yang dipakai adalah data pooling (data panel). Data pooling merupakan kombinasi antara data runtut waktu (time series) 
dan silang tempat (cross section). Panel memberikan data yang lebih banyak dan lebih informatif.

Sumber data dalam penelitian ini adalah data sekunder. Data sekunder adalah data yang telah dikumpulkan oleh lembaga pengumpul data dan dipublikasikan kepada masyarakat pengguna data (Kuncoro, 2003). Data sekunder berupa laporan tahunan perusahaan.

Populasi dalam penelitian ini adalah perusahaan Badan Usaha Milik Negara (BUMN) dan perusahaan Badan Usaha Milik Swasta (BUMS) sektor non keuangan (perbankan, asuransi, sekuritas, dan leasing). Kemudian, difokuskan kepada BUMN dan BUMS yang telah go public, dengan asumsi bahwa perusahaan BUMN dan BUMS yang go public telah diwajibkan menyampaikan laporan keuangan dan tahunan kepada publik sehingga mempermudah peneliti untuk melakukan identifikasi. Dari populasi tersebut, kemudian diambil sampel penelitian dengan menggunakan metode purposive sampling sesuai dengan jenis dan kriteria yang dibutuhkan.

Kriteria pengambilan sampel penelitian melalui metode purposive sampling adalah sebagai berikut: (I) Seluruh perusahaan BUMN dan BUMS yang terdaftar pada Bursa Efek Indonesia (BEI) periode tahun 2013 - 20I5. (2) Perusahaan BUMN dan BUMS yang tergolong sektor non keuangan. (3) Perusahaan BUMN dan BUMS yang menerbitkan Laporan Tahunan secara rutin dari tahun 2013 - 2015. (4) Perusahaan BUMN dan BUMS dengan pajak penghasilan positif antara tahun 2013 2015 .

Penelitian ini menggunakan data sekunder berupa laporan tahunan sejumlah 148 perusahaan non sektor keuangan yang terdaftar pada Bursa Efek Indonesia (BEI) mulai tahun 2013 sampai 20I5. Informasi yang diperoleh dari data laporan tahunan adalah laporan keuangan, data komisaris, dan data direksi.

Teknik analisis yang akan dipergunakan dalam penelitian ini ialah regresi dengan data panel. Pada regresi dengan data panel terdapat tiga kemungkinan model: (I) Model pooled least square; (2) Model efek tetap; (3) Model efek acak. 
Model analisis dalam penelitian ini adalah dengan menggunakan persamaan :

\section{Model I}

$\operatorname{CashETR}_{i . t}=\alpha_{i}+\beta_{1}$ POLCON $_{i . t}+\beta_{2}$ POLCON2 $2_{i . t}+\beta_{3}$ GROWTH $H_{i . t}+$ $\beta_{4}$ FIRMSIZE $_{i . t}+\beta_{5}$ ROA $_{i . t}+\beta_{6}$ CIR $_{i . t}+\beta_{7} L E V_{i . t}+\beta_{8} I_{N V I N T_{i . t}}+e_{i . t}$

\section{Model 2}

GAAPETR $_{i . t}=\alpha_{i}+\beta_{1}$ POLCON $_{i . t}+\beta_{2}$ POLCON2 $_{i . t}+\beta_{3}$ GROWTH $_{i . t}+$ $\beta_{4}$ FIRMSIZE $_{i . t}+\beta_{5}$ ROA $_{i . t}+\beta_{6}$ CIR $_{i . t}+\beta_{7} L E V_{i . t}+\beta_{8}{I N V I N T_{i . t}}+e_{i . t}$

\section{Model 3}

CurrentETR $_{i . t}=\alpha_{i}+\beta_{1}$ POLCON $_{i . t}+\beta_{2}$ POLCON2 $2_{i . t}+\beta_{3}$ GROWTH $_{i . t}+$ $\beta_{4}$ FIRMSIZE $_{i . t}+\beta_{5}$ ROA $_{i . t}+\beta_{6}$ CIR $_{i . t}+\beta_{7} L E V_{i . t}+\beta_{8}{I N V I N T_{i . t}}+e_{i . t}$

\section{Keterangan :}

CashETR $_{\text {i.t }} \quad=$ Cash Effective tax rate perusahaan $\mathrm{i}$ pada tahun $\mathrm{t}$

GAAPETR $_{i . t} \quad=$ GAAP Effective tax rate perusahaan $\mathrm{i}$ pada tahun $\mathrm{t}$

CurrentETR $R_{i . t}=$ Current Effective tax rate perusahaan $\mathrm{i}$ pada tahun $\mathrm{t}$

POLCON $1_{i . t} \quad=$ koneksi politik aspek kepemilikan saham pemerintah perusahaan $\mathrm{i}$ pada tahun $\mathrm{t}$

POLCON2 ${ }_{i . t}=$ dummy variabel, koneksi politik melalui komisaris perusahaan $\mathrm{i}$ pada tahun $\mathrm{t}$

GROWTH $_{\text {i.t }}=$ logaritma natural EBIT perusahaan $\mathrm{i}$ pada tahun $\mathrm{t}$

FIRMSIZE $E_{i . t}=$ logaritma natural total asset perusahaan $\mathrm{i}$ pada tahun ke $\mathrm{t}$

$R O A_{i . t} \quad=$ Return of Asset perusahaan $\mathrm{i}$ pada tahun ke $\mathrm{t}$

$C I R_{i . t}=$ capital intensity ratio perusahaan $\mathrm{i}$ pada tahun ke $\mathrm{t}$

$L E V_{i . t} \quad=$ Leverage perusahaan $\mathrm{i}$ pada tahun ke $\mathrm{t}$

$I_{N V I N T}$ i.t = inventory intensity ratio perusahaan $\mathrm{i}$ pada tahun ke $\mathrm{t}$

\section{HASIL DAN PEMBAHASAN}

\section{Hasil Empiris}

Pemilihan model yang terbaik pada regresi data panel diawali dengan melakukan uji chow untuk memilih antara model koefisien tetap (pooled regression/common effect model) dengan fixed effect model. Hasil dari pengujian uji chow kepada ketiga model 
adalah nilai probabilitas Chi Square adalah $0,000<$ sig 0,05, maka disimpulkan fixed effect model lebih baik dari pada common effect model.

Kemudian peneliti melakukan uji hausman untuk memilih antara fixed effect model atau random effect model. Hasil dari uji hausman dari ketiga model adalah nilai probabilitas diatas taraf signifikasi 0,05 , yakni $0,285,0,182$, dan 0, I73. Maka dapat disimpulkan model regresi data panel yang digunakan adalah random effect model.

Tabel I menunjukan hasil dari regresi data panel melalui model efek random. Regresi data panel yang dilakukan sebanyak tiga kali. Petama, pengujian regresi data panel dengan menggunakan seluruh proksi pada variabel independen serta variabel kontrol dan Current ETR sebagai variabel dependen. Pengujian kedua, menggunakan GAAP ETR dan pengujian ketiga menggunakan Cash ETR sebagai variabel dependen dengan asumsi yang sama untuk proksi variabel independen serta variabel kontrolnya.

Hasil analisis regresi data panel di Tabel I diperoleh nilai adj R Square rata-rata 0.15 atau $15 \%$ yang mengindikasi bahwa variabilitas variabel independen dan variabel kontrol yang terdiri dari koneksi politik, pertumbuhan laba, ukuran perusahaan, return of asset, capital intensity ratio, leverage dan inventory intensity ratio adalah mampu menjelaskan sebesar 15\%. 85\% sisanya adalah dijelaskan oleh variabel lain di luar model.

Berdasarkan hasil pada tabel, disimpulkan bahwa variabel yang secara signifikan berpengaruh terhadap Current ETR adalah koneksi politik melalui hubungan komisaris, tingkat pertumbuhan laba, ukuran perusahaan. Kemudian variabel yang secara signifikan yang mempengaruhi GAAP ETR adalah koneksi politik melalui hubungan komisaris, tingkat pertumbuhan laba, ukuran perusahaan, dan inventory intensity ratio. Sedangkan variabel yang signifikan mempengaruhi Cash ETR adalah koneksi politik melalui hubungan komisaris, tingkat pertumbuhan laba, ukuran perusahaan, dan ROA. 
Tabel I. Hasil Regresi Panel

\begin{tabular}{|c|c|c|c|c|}
\hline Variabel & $\begin{array}{l}\text { Curr. Tax } \\
\text { ETR (YI) }\end{array}$ & $\begin{array}{l}\text { GAAP ETR } \\
\text { (Y2) }\end{array}$ & $\begin{array}{l}\text { CASH } \\
\text { ETR (Y3) }\end{array}$ & Kesimpulan \\
\hline \multirow{2}{*}{ Intersept ( C ) } & 0.05511 & 0.135351 & -1.302114 & \\
\hline & 0.7469 & 0.3624 & 0.1438 & \\
\hline \multirow{2}{*}{ POLCONI (XI) } & 0.016542 & 0.056757 & 0.129557 & \\
\hline & $0.77 \mathrm{I}$ & 0.2556 & 0.6533 & \\
\hline \multirow{2}{*}{ POLCON2 (X2) } & 0.060262 & 0.029916 & 0.30566 & \\
\hline & $0.0300 *$ & $0.0219 *$ & $0.0299 *$ & \\
\hline \multirow{2}{*}{ GROWTH (X3) } & -0.067273 & -0.056796 & -0.482229 & \\
\hline & $0.0000 *$ & $0.0000 *$ & $0.0000 *$ & \\
\hline \multirow{2}{*}{ FIRMSIZE (X4) } & 0.067049 & 0.054413 & 0.494748 & $\mathbf{H I}$ \\
\hline & $0.0000 *$ & $0.0000^{*}$ & $0.0000 *$ & Diterima \\
\hline \multirow{2}{*}{ ROA (X5) } & 0.107236 & 0.128053 & $1.316 \mid 44$ & \\
\hline & 0.2797 & 0.1107 & $0.0426^{*}$ & \\
\hline \multirow{2}{*}{ CIR (X6) } & 0.021321 & 0.018176 & 0.12832 & \\
\hline & 0.2033 & 0.1749 & 0.2656 & \\
\hline \multirow{2}{*}{ LEV (X7) } & 0.047891 & 0.090402 & -0.553165 & \\
\hline & 0.4573 & 0.0991 & 0.121 & \\
\hline \multirow{2}{*}{ INVINT (X8) } & 0.026792 & 0.067981 & 0.097206 & \\
\hline & 0.4677 & $0.0231 *$ & 0.6857 & \\
\hline Adj R Square & 0.142456 & 0.149257 & 0.158813 & \\
\hline F Statistic & $10.19897^{*}$ & $10.71514^{*}$ & II.45456* & \\
\hline$*$ Sig 0,05 & & & & \\
\hline
\end{tabular}

Berdasarkan hasil dari ketiga pengujian data panel, memperlihatkan bahwa koneksi politik melalui hubungan dewan komisaris berpengaruh positif secara signifikan terhadap agresivitas pajak melalui proksi tingkat efektivitas pajak. Dengan demikian bahwa hipotesis penelitian yang menyatakan bahwa koneksi politik berpengaruh negatif terhadap agresivitas pajak adalah diterima dengan arah pengaruh yang berlawanan, yakni berpengaruh positif.

\section{Pembahasan}

Hasil dari pengujian koneksi politik melalui aspek kepimilikan pemerintah adalah berpengaruh positif namun tidak signifikan, namun koneksi politik melalui hubungan komisaris memperlihatkan hasil yang signifikan dengan berpengaruh positif terhadap agresivitas pajak. Hal ini bertentangan dengan Zhang (20I2) yang menunjukan bahwa koneksi politik berpengaruh negatif terhadap agresivitas pajak namun hasil penelitian ini 
juga mendukung hasil penetian yang dilakukan sebelumnya (Adhikari, 2006) yang menunjukan bahwa koneksi politik berpengaruh positif terhadap agresivitas pajak.

Variabel kontrol yang berpengaruh secara signifikan terhadap agresivitas pajak adalah tingkat pertumbuhan laba, ukuran perusahaan, return of asset, dan inventory intensity ratio. Untuk variabel return of asset, capital intensity ratio dan leverage berpengaruh secara tidak signifikan terhadap agresivitas pajak.

\section{SIMPULAN}

Penelitian ini dilakukan untuk menguji pengaruh koneksi politik melalui kepemilikan saham pemerintah dan aspek hubungan komisaris terhadap agresivitas pajak yang diukur melalui proksi Current ETR, GAAP ETR, dan Cash ETR. Variabel lainya yang diduga berpengaruh terhadap penelitian yang dilakukan adalah tingkat pertumbuhan laba, ukuran perusahaan, return of asset, capital intensity ratio, leverage, dan inventory intensity ratio.

Hasil pengujian yang menunjukan bahwa koneksi politik melalui hubungan komisaris berpengaruh positif terhadap agresivitas pajak adalah menunjukan koneksi politik yang dilakukan oleh perusahaan baik itu BUMN maupun BUMS adalah untuk melakukan lobby dengan pemerintah untuk menghindari pemeriksaan pajak, pengajuan pengurangan denda pajak maupun tindakan lain yang tergolong tax evasion atau tax agreesiveness. Koneksi politik yang dilakukan akan memberikan pengaruh baik atau positif terhadap tax agreesiveness yang disebut dengan Political Favoritism Effect.

\section{PUSTAKA ACUAN}

Adhikari, A., Derashid, C., \& Zhang, H. (2006). Public policy, political connections, and effective tax rates: Longitudinal evidence from Malaysia. Journal of Accounting and Public policy, 25 (5): 574-595.

Andreoni, J., Erard, B., \& Feinstein, J. (1998). Tax compliance. Journal of economic literature, 36(2): 818-860. 
Chen, S., Chen, X., Cheng, Q., \& Shevlin, T. (2010). Are family firms more tax aggressive than non-family firms? Journal of Financial Economics, 95 (I): $4|-6|$.

Dyreng, S. D., Hanlon, M., \& Maydew, E. L. (20/0). The effects of executives on corporate tax avoidance. The Accounting Review, 85(4): I I63-I I89.

Fisman, R. (200I). Estimating the value of political connections. The American economic review, 9I(4): I095-I I02.

Frank, M. M., Lynch, L. J., \& Rego, S. O. (2009). Tax reporting aggressiveness and its relation to aggressive financial reporting. The Accounting Review, 84(2), 467-496.

Gomez, E. T. (2009). The rise and fall of capital: Corporate Malaysia in historical perspective. Journal of Contemporary Asia, 39(3), 345-38I.

Hanlon, M., \& Heitzman, S. (2010). A review of tax research. Journal of Accounting and Economics, 50(2): 127-178.

Hanlon, M., \& Slemrod, J. (2009). What does tax aggressiveness signal? Evidence from stock price reactions to news about tax shelter involvement. Journal of Public Economics, 93 (I): |26-|4|.

Harahap, S. S. (20II). Teori Akuntansi, Edisi Revisi, Cetakan Kelima, PT. Raja Grafindo Perseda, Jakarta. Terjemahan. Edisi Ketujuh. Jakarta: Penerbit Salemba Empat.

Jensen, M. C. (1986). Agency costs of free cash flow, corporate finance, and takeovers. The American economic review, 76(2): 323-329.

Kuncoro, M. (2003). Metode riset untuk bisnis \& ekonomi: bagaimana meneliti \& menulis tesis. Jakarta: Erlangga.

Mclntyre, R. S., \& Nguyen, T. C. (2000). Corporate income taxes in the 1990s: Institute on Taxation and Economic Policy Washington, DC.

Sugiyono, M. P. P. (2007). Pendekatan Kuantitatif. Kualitatif, dan R\&D, Bandung: Alfabeta.

Swingly, C., \& Sukartha, I. (2015). Pengaruh Karakter Eksekutif, Komite Audit, Ukuran Perusahaan, Leverage dan Sales Growth Pada Tax Avoidance. E-Jurnal Akuntansi, 10(I): 47-62. 
Zhang, H., Li, W., \& Jian, M. (20I2). How does state ownership affect tax avoidance? Evidence from China: Working Paper At, Singapore Management University.

Zimmerman, J. L. (1983). Taxes and firm size. Journal of Accounting and Economics, 5: 119-149. 